\title{
Characterization of outdoor air pollution from solid fuel combustion in Xuanwei and Fuyuan, a rural region of China
}

Wei Hu ( $\nabla$ wei.hu@nih.gov)

National Cancer Institute https://orcid.org/0000-0002-4138-7905

George Downward

Universiteit Utrecht

Jason Y.Y Wong

National Cancer Institute

\section{Boris Reiss}

University of Arizona

Nathaniel Rothman

National Cancer Institute

Lutzen Portengen

Universiteit Utrecht

Jihua Li

Qujing Center for Diseases Control and Prevention

Rena R. Jones

National Cancer Institute

Yunchao Huang

Yunnan Cancer Hospital

Kaiyun Yang

Yunnan Cancer Hospital

Ying Chen

Yunnan Cancer Hospital

Jun $\mathrm{Xu}$

University of Hong Kong

Jun $\mathrm{He}$

Qujing Center for Diseases Control and Prevention

Bryan Bassig

National Cancer Institute

Wei Jie Seow

National University of Singapore

Dean H. Hosgood

Albert Einstein College of Medicine

Linlin Zhang

China Institute of Geo-environment Monitoring

Guoping Wu

China National Environmental Monitoring Center

\section{Fusheng Wei}

China National Environmental Monitoring Center

Roel Vermeulen

Universiteit Utrecht

Qing Lan

National Cancer Institute

\section{Research}

Keywords: Outdoor air pollution, Solid fuel, PM2.5, Exposure assessment, PAHs

Posted Date: January 9th, 2020

DOI: https://doi.org/10.21203/rs.2.20541/v1

License: () (1) This work is licensed under a Creative Commons Attribution 4.0 International License. Read Full License 
Version of Record: A version of this preprint was published at Scientific Reports on July 9th, 2020. See the published version at https://doi.org/10.1038/s41598-020-68229-2. 


\begin{abstract}
Background: Outdoor air pollution is a growing public health concern, particularly in urban settings. However, there are limited epidemiological data on outdoor air pollution in rural areas with substantial levels of air pollution attributed to solid fuel burning for household cooking and heating. Xuanwei and Fuyuan are rural counties in China where the domestic combustion of locally sourced bituminous ("smoky") coal has been associated with the highest lung cancer rates in China. We previously assessed indoor and personal air pollution exposures in this area; however, the influence of indoor coal combustion and household ventilation on outdoor air pollution has not been assessed.

Methods: We measured outdoor fine particulate matter (PM2.5), species of polycyclic aromatic hydrocarbons (PAHs) including naphthalene (NAP) and the known carcinogen benzo(a)pyrene (BaP), sulfur dioxide (SO2), and nitrogen dioxide (NO2) over two consecutive 24-hour sampling periods in 29 villages. Half of the villages were revisited two to nine months after the initial sampling period to repeat all measurements.

Results and Conclusion: The overall geometric mean (GM) of outdoor PM2.5, BaP, NAP, and NO2 were $45.3 \mu \mathrm{g} / \mathrm{m3}, 9.7 \mathrm{ng} / \mathrm{m} 3,707.7 \mathrm{ng} / \mathrm{m} 3$, and $91.5 \mu \mathrm{g} / \mathrm{m} 3$, respectively. Using linear mixed effects models, we found that burning smoky coal was associated with higher outdoor BaP concentrations (GM ratio $(G M R)=2.79)$ and lower outdoor SO2 detection rates $(G M R=0.43)$, compared to areas burning smokeless coal. Areas with predominantly ventilated stoves ( $>50 \%$ of stoves) had higher outdoor BaP (GMR=1.49) compared to areas with fewer ventilated stoves. These results show that outdoor air pollution in a rural region of China was associated with the type of coal used for cooking and heating indoors and the presence of stove ventilation. Our findings suggest that efforts to reduce indoor air pollution have resulted in higher outdoor air pollution levels. Further reducing adverse health effects in rural villages from household coal combustion will require the use of cleaner fuel types.
\end{abstract}

\title{
Introduction
}

Outdoor air pollution is a major environmental health concern that was linked to 3.7 million deaths worldwide in 2012 (six percent due to lung cancer) and 4.2 million deaths in 2015 (16.5\% due to lung cancer) [1-3]. Outdoor air pollution is considered a leading environmental cause of lung cancer by the International Agency for Research on Cancer (IARC) which recently classified outdoor air pollution and particulate matter (PM) as a Group 1 carcinogen (carcinogenic to humans) [4-6].

While automobile traffic is the predominant source of outdoor air pollution in urban areas, this is not the case in rural, underdeveloped areas where local sources such as cooking and heating stoves contribute significantly to air pollution levels [7]. Approximately $40 \%$ of the global population uses solid fuels (e.g. wood, coal) for heating or cooking. While many epidemiological studies focus on the health impacts of outdoor air pollution in urban areas, outdoor air pollution and its adverse health effects in rural areas are often overlooked [7]. More than $60 \%$ of the Chinese population lives in rural regions. In this population, household air pollution (HAP) due to domestic combustion of solid fuels contributes significantly to the total burden of disease [8]; however, epidemiological data on outdoor air pollution exposure in rural China is limited. Xuanwei and Fuyuan are rural counties located in Southwestern China that have elevated rates of nonmalignant and malignant lung diseases including the highest lung cancer rate in China that is directly associated with HAP from bituminous ("smoky") coal $[9,10]$. We previously reported indoor and personal exposure levels to $\mathrm{PM}_{2.5}$, polycyclic aromatic hydrocarbons (PAHs), black carbon, $\mathrm{NO}_{2}$, and $\mathrm{SO}_{2}$ from burning solid fuels in Xuanwei and Fuyuan [11-14]; and reported outdoor measurements of black carbon were positively correlated with the level of indoor measurements [14]. Additionally, we previously reported that there was variation in lung cancer risk for specific subtypes of smoky coal mined from different Xuanwei geological coal deposits $[15,16]$, while improving home ventilation by installing stoves with chimneys and converting to portable stoves was associated with both a reduction in lung cancer rates and specific HAP constituents in this region [17, 18]. However, the contribution to neighborhood-level outdoor air pollution from both household ventilation and the indoor burning of coal mined from various coal deposits has not been assessed in this region. Given the clear need for outdoor air pollution research in rural settings, especially within China, we evaluated outdoor air pollution concentrations and the potential factors associated with those levels in Xuanwei and Fuyuan.

\section{Materials And Methods}

\section{STUDY DESIGN AND AIR POLLUTION MEASUREMENTS}

The exposure assessment study design and population have been described in detail elsewhere [11]. We reported here the part of outdoor air measurement. Briefly, outdoor air measurements were taken between August 2008 and June 2009 from 29 selected villages in Xuanwei and Fuyuan as part of a large casecontrol study of lung cancer, and a cross-sectional molecular epidemiological study. Villages were selected to represent all major geological coal deposit areas based on a local geologic analysis of coal-type in Xuanwei and Fuyuan counties. In each selected village, four or five households were selected to conduct personal and indoor exposure measurements, while outdoor air measurements were conducted in a central location within each village in phase I. In phase II, approximately half of the villages $(n=16)$ and households were visited for a second round of repeated measurements two to nine months later.

\section{VILLAGE BACKGROUND INFORMATION}

Background demographic information for each village was collected through an in-person interview with either a local doctor or the village head. Global Positioning System (GPS) coordinates were recorded on-site. Survey information included: house types and ventilation, fuels used for cooking and heating, stove types, main coal mines providing coal to the village, village altitude, total population, land area in $\mathrm{km}^{2}$, percentage of households having a television set, average household income, and presence of nearby industries. Distribution of some variables were shown in Table 1. 
Table 1

Environmental and meteorological characteristics of the villages

\begin{tabular}{|c|c|c|c|}
\hline Characteristics & $N(k)^{a}$ & AM (SD) & $\begin{array}{l}\text { Median } \\
\text { (25\%,75\% percentile) }\end{array}$ \\
\hline Daily average outside temperature, ${ }^{\circ} \mathrm{C}$ & $88(29)$ & $10.7(5.8)$ & $11.2(5.6,16.4)$ \\
\hline Daily average outside humidity, $\%$ & $88(29)$ & $78(16.8)$ & $82.2(69.9,90)$ \\
\hline Population & $29(29)$ & $840(750)$ & $570(420,920)$ \\
\hline \multicolumn{4}{|c|}{ Proportion of chimney stoves in a village, $\mathrm{k}(\%)$} \\
\hline$>50 \%$ & $22(75.9)$ & & \\
\hline$\leq 50 \%$ & $7(24.1)$ & & \\
\hline \multicolumn{4}{|l|}{ Factory within 5 km, k(\%) } \\
\hline Yes & $4(13.8)$ & & \\
\hline No & $21(72.4)$ & & \\
\hline Unknown & $4(13.8)$ & & \\
\hline \multicolumn{4}{|l|}{ Coal mine within 5 km, k(\%) } \\
\hline Yes & $4(13.8)$ & & \\
\hline No & $21(72.4)$ & & \\
\hline Unknown & $4(13.8)$ & & \\
\hline \multicolumn{4}{|l|}{ Power plants within 5 km, k(\%) } \\
\hline Yes & $3(10.3)$ & & \\
\hline No & $22(75.9)$ & & \\
\hline Unknown & $4(13.8)$ & & \\
\hline
\end{tabular}

\section{OUTDOOR SAMPLE COLLECTION AND ANALYSIS}

An ambient air monitoring station was installed at a central location within each village away from any direct sources of emissions (e.g. chimneys). The air monitoring methods that were used were similar to those used to measure indoor air pollution and are described in detail [11, 12, 14]. In brief, samples of fine PM and associated particle phase PAHs were collected on $37 \mathrm{~mm}$ Teflon filters using a cyclone with an aerodynamic cut-off of $2.5 \mu \mathrm{m}$ (model BGI, GK $2.05 \mathrm{SH}$ ) at a flow rate of $3.5 \mathrm{~L} / \mathrm{min}( \pm 20 \%)$. XAD-2 sorbent tubes were used to measure gas phase PAHs at an air flow rate of $100 \mathrm{~mL} / \mathrm{min}$. Particulate mass was measured by pre- and post-weighing of the filters in an environmentally-controlled weighing room using a microbalance at $1 \mu \mathrm{g}$ accuracy. PAH extraction from the Teflon filters and the XAD-2 sorbent tubes was performed using the US EPA 3540C-1996 (Soxhlet extraction) method to determine concentrations of 16 PAHs by a gas chromatograph connected to a mass spectrometer (Shimadzu QP2010 Plus). Passively diffusing OGAWA badges were deployed to collect measurements of $\mathrm{NO}_{2}$ and $\mathrm{SO}_{2}$. Flow injection analysis and ion chromatography were used to determine the concentrations of $\mathrm{NO}_{2}$ and $\mathrm{SO}_{2}$, respectively. In addition, a weather station (WeatherLink ${ }^{\circledR}$ Wireless Vantage Pro2) was deployed to record meteorological factors (e.g. temperature, wind speed, humidity, rainfall amount). Two sequential 24-hr outdoor air measurements were conducted in each village in parallel with indoor and personal measurements.

\section{STATISTICAL ANALYSES}

Normal probability plots indicated that the measured values could be best described by a log-normal distribution; therefore, outdoor air pollution concentrations were natural log-transformed to approximate normal distributions for the statistical analyses that were conducted. Outdoor measurements were summarized as arithmetic means (AM), geometric means (GM), and geometric standard deviations (GSD) by coal deposit. Meteorological factors are summarized as AM, standard deviations (SD), and medians. Spearman correlations were calculated between concentrations of outdoor and indoor pollutants. Analysis of variance (ANOVA) and Tukey Honestly Significant Difference (HSD) testing was performed on log-transformed values to assess differences between coal deposits, fuel types, stove ventilation, and season. Due to the large proportion of undetectable values of $\mathrm{SO}_{2}$ measurements (73.9\%), detection rate (\%Detect) was calculated for each coal deposit and overall region. Linear mixed effect models were used to identify variables which may be associated with outdoor $\mathrm{PM}_{2.5}, \mathrm{BaP}, \mathrm{NAP}$, and $\mathrm{NO}_{2}$, while a mixed effects logistic model was used for $\mathrm{SO}_{2}$. Villages were assigned random effects with a variancecomponents covariance structure. Multiple variables were considered for inclusion as fixed effects including coal deposits, season (winter, spring, summer, autumn), proportion of ventilated stoves (i.e. chimneys) in a village, meteorological factors, proportion of solid fuel types in a village to heat rooms or cook, proportion of stove types used in a village, type of coal mines (i.e. smoky coal or smokeless coal), altitude, village area, population size, nearby industry, average indoor concentration of the pollutant measured in a village, average income and other surrogates of socioeconomic status such as proportion of households having a TV set. Inclusion of variables in the final model was based on the combination of their influence on the Akaike information criterion (AIC) score. The linear mixed effect model can be expressed with the following equation: 


$$
y_{i j}=\mu+\beta_{1} x_{1}+\beta_{2} x_{2} \ldots \beta_{n} x_{n}+b_{1} I_{i}+b_{2} J_{i j}+\varepsilon_{i j}
$$

Where $\mathrm{y}_{\mathrm{ij}}$ represents the natural log-transformed value of outdoor pollutant concentration being modeled for coal deposit $\mathrm{i}$ in village $\mathrm{j} ; \mu$ represents the intercept value (i.e., the log-transformed value for the reference group); $\beta_{1}$ through $\beta_{n}$ represent the fixed effect variable coefficients for variables $x_{1}$ through $x_{n} ; b_{1} l_{i}$ represents the coefficient for coal deposit $\mathrm{i} ; \mathrm{b}_{2} \mathrm{~J}_{\mathrm{ij}}$ represents the random effect coefficient for village $\mathrm{j}$ from coal deposit $\mathrm{i}$; and $\varepsilon_{\mathrm{ij}}$ represents the error for village $\mathrm{j}$ in coal deposit i.

All analyses were carried out using SAS version 9.4 software (SAS Institute, Cary, NC).

\section{Results}

Figure 1 shows the distribution of the 29 villages (16 of them were visited at both Phases I and II) and coal mine regions in Xuanwei and Fuyuan counties. Most villages were located in smoky coal mine areas in the center, east, north, and south parts of Xuanwei. Several villages in southwestern Xuanwei were in a historically smokeless coal mine region (27), where farmers have changed to wood. In Fuyuan, smokeless coal mines are predominantly located in the south, while smoky coal mines are in the north.

\section{BACKGROUND INFORMATION OF VILLAGES}

Background measurement information about the villages and meteorological factors are summarized in Table 1. Less than $14 \%$ of the villages were within $5 \mathrm{~km}$ of a known factory, mine, or power station. The average village population size was 840 (750 SD). In the past, smoky coal was used in areas of Xuanwei and Fuyuan that had undergone stove improvement interventions, including the installation of chimneys, in an effort to reduce HAP [17, 18]. As a result, more than half of all households in 22 of the 29 villages (75.9\%) included stoves ventilated with chimneys.

\section{OUTDOOR POLLUTION IN COAL DEPOSITS}

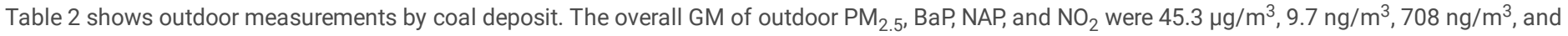
$91.5 \mathrm{\mu g} / \mathrm{m}^{3}$ respectively. The overall detection rate of $\mathrm{SO}_{2}$ was $26.1 \%$. Outdoor pollutant concentrations or detection rates (\%Detect) were similar between the two counties (GM(GSD): $51.6(1.7)$ and $40.2(2.0) \mu \mathrm{g} / \mathrm{m}^{3}$ for $\mathrm{PM}_{2.5} ; 10.5(1.7)$ and 8.9(1.6) $\mathrm{ng} / \mathrm{m}^{3}$ for BaP; 730(2.3) and 678(2.6) ng/m³ for NAP; 93.2(1.4) and 89.7(1.5) $\mathrm{\mu g} / \mathrm{m}^{3}$ for $\mathrm{NO}_{2}$, and \%Detect: 34.8 and $34.1 \%$ for $\mathrm{SO}_{2}$, in Xuanwei and Fuyuan, respectively). Based on an ANOVA test there is significant variation within each coal deposit for $\mathrm{PM}_{2.5}$ absorbance $\left(\mathrm{PM}_{\mathrm{abs}}\right)(\mathrm{p}<0.05)$. A Tukey HSD test further reveals that $\mathrm{PM}_{\mathrm{abs}}$ in villages located in several smoky coal deposits (GM(GSD): 5.8(1.7) - 7.7(1.3) × 10-5/m) were significantly higher compared with villages located in smokeless coal deposits (GM(GSD): 3.3(1.4) × $\left.10^{-5} / \mathrm{m}\right)(\mathrm{p}<0.05)$

Table 2

Concentrations of outdoor air pollutants in villages of Xuanwei and Fuyuan by coal deposit

\begin{tabular}{|c|c|c|c|c|c|c|c|c|c|c|c|c|c|c|c|c|}
\hline \multirow{2}{*}{$\begin{array}{l}\text { Coal Deposit } \\
\text { in region }\end{array}$} & \multicolumn{3}{|c|}{$\mathrm{PM}_{2.5}\left(\mu \mathrm{g} / \mathrm{m}^{3}\right)$} & \multicolumn{3}{|c|}{$\mathrm{BaP}\left(\mathrm{ng} / \mathrm{m}^{3}\right)$} & \multicolumn{2}{|c|}{$\operatorname{NAP}\left(\mathrm{ng} / \mathrm{m}^{3}\right)$} & \multicolumn{2}{|l|}{$\mathrm{SO}_{2}$} & \multicolumn{3}{|c|}{$\mathrm{NO}_{2}\left(\mu \mathrm{g} / \mathrm{m}^{3}\right)$} & \multicolumn{3}{|c|}{$\mathrm{PM}_{\mathrm{abs}}($} \\
\hline & $\mathbf{N}$ & $\mathrm{AM}^{\mathrm{a}}$ & $\mathrm{GM}(G S D)^{b}$ & $\mathbf{N}$ & AM & GM(GSD) & $\mathbf{N}$ & AM & GM(GSD) & $\mathbf{N}$ & \%Detect & $\mathbf{N}$ & $\mathrm{AM}$ & GM(GSD) & $\mathbf{N}$ & A \\
\hline Overall & 85 & 53.1 & $45.3(1.8)$ & 51 & 11.1 & $9.7(1.7)$ & 58 & 1045.8 & $707.7(2.4)$ & 88 & 26.1 & 87 & 97.6 & $91.5(1.4)$ & 66 & 5 \\
\hline Xuanwei & 41 & 58.1 & $51.6(1.7)$ & 28 & 12.1 & $10.5(1.7)$ & 34 & 1078.8 & $729.9(2.3)$ & 44 & 34.8 & 44 & 97.5 & $93.2(1.4)$ & 34 & 6 \\
\hline $1,2,4,7,8 \%$ & 20 & 56.8 & $47.4(1.8)$ & 14 & 12.7 & $10.8(1.8)$ & 20 & 1058.4 & $813.6(2.2)$ & 22 & 18.2 & 22 & 101.7 & $97.8(1.3)$ & 18 & 6 \\
\hline $9 \%$ & 4 & 70.1 & $67.9(1.3)$ & 4 & 13.7 & $12.0(1.8)$ & 4 & 629.0 & $620.0(1.2)$ & 4 & 25 & 4 & 118.5 & $116.8(1.2)$ & 4 & 7. \\
\hline $10 \%$ & 4 & 59.1 & $57.9(1.3)$ & 2 & 19.8 & $19.8(1.0)$ & 0 & - & - & 4 & 50 & 4 & 113.0 & $107.5(1.4)$ & 4 & 7. \\
\hline $\mathrm{LS}^{\star}, \%$ & 4 & 49.2 & $47.8(1.3)$ & 3 & 6.2 & $6.1(1.2)$ & 4 & 2282.6 & $682.8(5.3)$ & 4 & 25 & 4 & 85.1 & $83.7(1.2)$ & 2 & 5 \\
\hline Fuyuan & 44 & 48.5 & $40.2(2.0)$ & 23 & 9.9 & $8.9(1.6)$ & 24 & 999.2 & $677.5(2.6)$ & 44 & 34.1 & 43 & 97.7 & $89.7(1.5)$ & 32 & 4 \\
\hline $12,13,14,38^{\%}$ & 10 & 58.8 & $50.8(1.8)$ & 8 & 9.2 & $8.7(1.5)$ & 8 & 1272.8 & 1093.9(1.9) & 10 & 20 & 9 & 88.9 & $87.6(1.2)$ & 4 & 7 \\
\hline $16,17,19 \%$ & 22 & 48.5 & 42.1(1.8) & 13 & 11.0 & $10.1(1.6)$ & 9 & 1276.0 & 827.1(3.2) & 22 & 27.3 & 22 & 97.5 & $92.0(1.5)$ & 18 & 4 \\
\hline $20,27^{\star \star *} \%$ & 21 & 48.3 & $39.0(2.2)$ & 7 & 8.4 & $7.4(1.7)$ & 13 & 475.2 & $413.0(1.7)$ & 22 & 31.8 & 22 & 92.8 & $81.7(1.6)$ & 16 & 3 \\
\hline
\end{tabular}

${ }^{a} \mathrm{AM}=$ Arithmetic Mean. ${ }^{\mathrm{b}} \mathrm{GM}=$ Geometric Mean, GSD = Geometric Standard Deviation. ${ }^{\mathrm{c}} \mathrm{p}<0.05$ when compared with deposit 20,27 deposits via Tukey HSL located in deposit 27 in Xuanwei; ${ }^{* *}$ Deposit 27 is located in Xuanwei; ${ }^{\%}$ Deposit numbers refer to the map locations of each coal source shown in Fig. 1. NAP, $\mathrm{BaP}$, Benzo(a)pyrene; $\mathrm{SO}_{2}$, sulfur dioxide; $\mathrm{NO}_{2}$, nitrogen dioxide. ${ }^{\dagger} \mathrm{p}<0.05$ among coal deposits via ANOVA test, data were published in reference [14] 
Table 3 shows the concentrations of outdoor pollutants associated with coal type, stove ventilation, and season. Outdoor BaP and NAP concentrations in villages using smoky coal were significantly higher than those using smokeless coal (smoky coal vs smokeless coal, GM(GSD): 10.2(1.7) vs 5.7(1.4) $\mathrm{ng} / \mathrm{m}^{3}$ for $\mathrm{BaP}, 795(2.4)$ vs $303(1.6) \mathrm{ng} / \mathrm{m}^{3}$ for NAP); and $\mathrm{p}<0.05$ via Tukey HSD test. Further, $\mathrm{PM}_{2.5}$ concentrations were not significantly higher in these villages (smoky coal vs smokeless coal, GM(GSD): $47.7(1.7)$ vs $35.0(2.4) \mu \mathrm{g} / \mathrm{m}^{3}$ ). However, using smoky coal was associated with significantly lower outdoor $\mathrm{SO}_{2}$ \%Detect compared with using smokeless coal $(50.0 \%$ vs $21.6 \%$; $<0.05)$. Overall, villages with greater than $50 \%$ of the households using chimneys generally had higher outdoor $\mathrm{PM}_{2.5}, \mathrm{BaP}, \mathrm{NAP}$, and $\mathrm{NO}_{2}$ compared to those with $\leq 50 \%$ chimney use, although these differences were not statistically significant.

Table 3

Concentrations of outdoor air pollutants in villages of Xuanwei and Fuyuan, by coal type, stove type, and season

\begin{tabular}{|c|c|c|c|c|c|c|c|c|c|c|c|c|c|c|}
\hline & \multicolumn{3}{|c|}{$\mathrm{PM}_{2.5}\left(\mu \mathrm{g} / \mathrm{m}^{3}\right)$} & \multicolumn{3}{|c|}{$\mathrm{BaP}\left(\mathrm{ng} / \mathrm{m}^{3}\right)$} & \multicolumn{3}{|c|}{$\operatorname{NAP}\left(n g / m^{3}\right)$} & \multicolumn{2}{|l|}{$\mathrm{SO}_{2}$} & \multicolumn{3}{|c|}{$\mathrm{NO}_{2}\left(\mu \mathrm{g} / \mathrm{m}^{3}\right)$} \\
\hline & $\mathrm{N}$ & $\mathrm{AM}^{\mathrm{a}}$ & $\mathrm{GM}(\mathrm{GSD})^{\mathrm{b}}$ & $\mathrm{N}$ & $\mathrm{AM}^{\mathrm{a}}$ & $\mathrm{GM}(\mathrm{GSD})^{\mathrm{b}}$ & $\mathrm{N}$ & $\mathrm{AM}^{\mathrm{a}}$ & $\mathrm{GM}(\mathrm{GSD})^{\mathrm{b}}$ & $\mathrm{N}$ & \%Detect & $\mathrm{N}$ & $\mathrm{AM}^{\mathrm{a}}$ & $\mathrm{GM}(\mathrm{GSD})^{\mathrm{b}}$ \\
\hline \multicolumn{15}{|c|}{ Coal type from coalmines } \\
\hline Smokeless coal & 14 & 46.1 & $35.0(2.4)$ & 4 & 5.9 & $5.7(1.4)$ & 7 & 331 & $303(1.6)$ & 14 & 21.6 & 14 & 106.3 & $90.8(1.7)$ \\
\hline Smoky coal & 71 & 54.5 & $47.7(1.7)$ & 47 & 11.6 & $10.2(1.7)^{\mathrm{c}}$ & 51 & 1144 & $795(2.4)^{\mathrm{c}}$ & 74 & $50.0^{\mathrm{d}}$ & 73 & 95.9 & $91.6(1.4)$ \\
\hline \multicolumn{15}{|c|}{ Proportion of ventilated stoves in a village } \\
\hline$\leq 50 \%$ & 19 & 52.1 & $44.4(2.0)$ & 9 & 8.7 & $8.1(1.5)$ & 15 & 666 & $543(1.9)$ & 20 & 30.0 & 20 & 89.9 & $84.5(1.4)$ \\
\hline$>50 \%$ & 66 & 53.4 & $45.6(1.8)$ & 42 & 11.6 & 10.1(1.7) & 43 & 1178 & $776(2.5)$ & 68 & 25.0 & 67 & 99.9 & $93.7(1.4)$ \\
\hline \multicolumn{15}{|l|}{ Season } \\
\hline Autumn & 32 & 42.3 & $35.3(1.9)$ & 16 & 7.9 & $7.4(1.4)$ & 28 & 763.3 & $547.4(2.3)$ & 33 & 30.3 & 33 & 80.7 & $77.0(1.4)$ \\
\hline Spring & 25 & 51.2 & $43.9(1.9)$ & 21 & 13.4 & $11.9(1.7)^{\mathrm{e}}$ & 17 & 813.9 & $629.2(2.1)$ & 24 & 24.0 & 24 & 105.4 & $97.9(1.4)^{\mathrm{e}}$ \\
\hline Summer & 0 & - & - & 0 & - & - & 0 & - & - & 2 & 0.0 & 2 & 81.1 & $76.3(1.6)$ \\
\hline Winter & 28 & 67.2 & $62.2(1.5)^{\mathrm{e}}$ & 14 & 11.3 & $9.9(1.7)$ & 13 & 1957.7 & $1435.5(2.3)^{e, f}$ & 28 & 25.0 & 28 & 112.0 & $107.1(1.4)^{\mathrm{e}}$ \\
\hline $\begin{array}{l}{ }^{a} \mathrm{AM}=\text { Arithmetic } \\
{ }^{\mathrm{d}} \mathrm{p}<0.05 \text { when } \mathrm{c} \\
\text { with spring via } \mathrm{T}\end{array}$ & ean & $\begin{array}{l}\text { GM = } \\
\text { with }\end{array}$ & eometric Me & , & $\begin{array}{l}=\mathrm{Gec} \\
\text { her's }\end{array}$ & etric Stand & 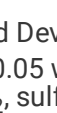 & $\begin{array}{l}\text { ion. }{ }^{c p} \\
\text { en com }\end{array}$ & $\begin{array}{l}.05 \text { when con } \\
\text { ed with autur }\end{array}$ & red $v$ & hey & , & $\begin{array}{l}\text { via Tu } \\
0.05 \mathrm{n}\end{array}$ & $\begin{array}{l}\text { HSD test. } \\
\text { compared }\end{array}$ \\
\hline
\end{tabular}

ANOVA testing revealed significant seasonal variation in concentrations of the four outdoor pollutants $(T a b l e ~ 3, p<0.05)$. Concentrations of $P M{ }_{2.5}, N A P, B a P$, and $\mathrm{NO}_{2}$ were lowest in autumn. $\mathrm{PM}_{2.5}$ levels were 1.8 times as high in winter than in autumn (GM: $62.2 \mathrm{vs} 35.3 \mu \mathrm{g} / \mathrm{m}^{3}, \mathrm{p}<0.05$ ). NAP was significantly higher in winter compared with either autumn or spring. Outdoor BaP in spring was the highest (GM: $\left.11.9 \mathrm{ng} / \mathrm{m}^{3}, \mathrm{p}<0.05\right)$ compared with levels in the autumn (GM: $7.4 \mathrm{ng} / \mathrm{m}^{3}$ ). Compared with levels in autumn $\left(\mathrm{GM}: 77.0 \mu \mathrm{g} / \mathrm{m}^{3}\right), \mathrm{NO}_{2}$ levels were significantly higher during the spring and winter $\left(\mathrm{GM}: 97.9\right.$ and $107.1 \mu \mathrm{g} / \mathrm{m}^{3}$, respectively). There was no significant difference for $\mathrm{SO}_{2}$ detection rates across seasons.

\section{CORRELATION BETWEEN OUTDOOR AND INDOOR AIR POLLUTION}

Outdoor $\mathrm{PM}_{2.5}$ concentrations were moderately correlated with median indoor $\mathrm{PM}_{2.5}$ concentrations that were measured in four to five households in each village (Spearman $\left.r_{s}=0.41, p<0.0001\right)$. Outdoor $\mathrm{NO}_{2}$ concentrations were also moderately correlated with median indoor $\mathrm{NO}_{2}$ concentrations $\left(r_{s}=0.43\right.$, $p<$ 0.0001). However, a relatively weaker correlation was found between outdoor and indoor BaP concentrations $\left(r_{s}=0.21, p=0.06\right)$.

\section{DETERMINANTS OF OUTDOOR POLLUTANTS}

Of all of the variables considered in the mixed models, coal type from the local coal mine, the percentage of homes in each village with chimney stoves, and season were identified as common factors contributing to outdoor $\mathrm{PM}_{2.5}, \mathrm{BaP}$, and $\mathrm{NAP}$ (Table 4). For $\mathrm{NO}_{2}$ only, the average indoor concentration was identified as a contributing factor to its corresponding outdoor concentration $(G M R=1.01, p<0.05)$. Coal type and the use of fire pits for cooking were associated with outdoor $\mathrm{SO}_{2}$ detection rates. 
Table 4

Significant determinants of outdoor air concentrations from mixed modeling

\begin{tabular}{|c|c|c|c|c|c|c|c|c|c|c|c|c|c|c|}
\hline & \multicolumn{3}{|c|}{ In-PM 2.5} & \multicolumn{3}{|c|}{ In-BaP } & \multicolumn{3}{|c|}{ In-NAP } & \multicolumn{3}{|l|}{$\mathrm{SO}_{2}$} & \multicolumn{2}{|l|}{ In- $\mathrm{NO}_{2}$} \\
\hline & $\beta$ & $95 \% \mathrm{Cl}$ & $\mathrm{GMR}^{\mathrm{a}}$ & $\beta$ & $95 \% \mathrm{Cl}$ & GMR & $\beta$ & $95 \% \mathrm{Cl}$ & GMR & $\beta$ & $95 \% \mathrm{Cl}$ & OR & $\beta$ & $95 \%$ \\
\hline \multicolumn{15}{|l|}{ Coal type } \\
\hline smokeless coal & ref. & & 1.00 & ref. & & 1.00 & ref. & & 1.00 & ref. & & 1.00 & & \\
\hline smoky coal & 0.31 & $-0.31,0.93$ & 1.36 & 1.02 & $0.29,1.76$ & 2.79 & 0.89 & $0.04,1.75$ & 2.44 & -0.85 & $-1.58,-0.12$ & 0.43 & not incl & ded \\
\hline \multicolumn{15}{|c|}{ Proportion of chimney stoves in a village } \\
\hline$\leq 50 \%$ & ref. & & 1.00 & ref. & & 1.00 & ref. & & 1.00 & & & & & \\
\hline$>50 \%$ & -0.02 & $-0.39,0.35$ & 0.98 & 0.40 & $0.01,0.79$ & 1.49 & 0.06 & $-0.53,0.64$ & 1.06 & & $\begin{array}{l}\text { not } \\
\text { included }\end{array}$ & & not incl & uded \\
\hline \multicolumn{15}{|l|}{ Season } \\
\hline autumn & ref. & & & ref. & & 1.00 & ref. & & 1.00 & & & & ref. & \\
\hline spring/summer ${ }^{b}$ & 0.19 & $-0.18,0.56$ & 1.21 & 0.52 & $0.21,0.84$ & 1.69 & 0.29 & $-0.14,0.71$ & 1.33 & & $\begin{array}{l}\text { not } \\
\text { included }\end{array}$ & & -0.04 & -0.21 \\
\hline winter & 0.62 & $0.25,0.99$ & 1.86 & 0.38 & $0.04,0.72$ & 1.46 & 1.15 & $0.65,1.65$ & 3.17 & & & & 0.17 & 0.00 \\
\hline \multicolumn{15}{|c|}{ Population, per 1,000} \\
\hline & 0.46 & $-0.04,0.95$ & 1.58 & \multicolumn{3}{|c|}{ not included } & \multicolumn{3}{|c|}{ not included } & \multicolumn{3}{|c|}{ not included } & \multicolumn{2}{|c|}{ not included } \\
\hline \multicolumn{15}{|c|}{ Use firepit to cook, $10 \%$} \\
\hline & \multicolumn{3}{|c|}{ not included } & \multicolumn{3}{|c|}{ not included } & \multicolumn{3}{|c|}{ not included } & 0.20 & $-0.31,0.71$ & 1.22 & \multicolumn{2}{|c|}{ not included } \\
\hline \multicolumn{15}{|c|}{ Averaged indoor $\mathrm{NO}_{2}, \mu \mathrm{g} / \mathrm{m}^{3}$} \\
\hline & \multicolumn{3}{|c|}{ not applicable } & \multicolumn{3}{|c|}{ not applicable } & \multicolumn{3}{|c|}{ not applicable } & \multicolumn{3}{|c|}{ not applicable } & 0.010 & 0.00 \\
\hline \multicolumn{15}{|l|}{ Coal deposit } \\
\hline 20,27 & \multicolumn{3}{|l|}{ ref. } & \multicolumn{2}{|l|}{ ref. } & 1.00 & \multicolumn{2}{|l|}{ ref. } & 1.00 & not inc & uded & & ref. & \\
\hline $1,2,4,7,8$ & -0.17 & $-0.79,0.44$ & 0.84 & -0.22 & $-0.85,0.41$ & 0.80 & -0.16 & $-0.95,0.63$ & 0.85 & & & & 0.18 & 0.01 \\
\hline 9 & -0.74 & $-2.13,0.66$ & 0.48 & -0.16 & $-0.91,0.59$ & 0.85 & -0.04 & $-1.17,1.08$ & 0.96 & & & & 0.51 & 0.21 \\
\hline 10 & -0.11 & $-0.98,0.77$ & 0.90 & 0.08 & $-0.81,0.96$ & 1.08 & - & - & - & & & & 0.31 & -0.01 \\
\hline LS & -01.40 & $-2.88,0.09$ & 0.25 & -0.81 & $-1.61,-0.01$ & 0.44 & -0.38 & $-1.53,0.76$ & 0.68 & & & & 0.15 & $-0.1 \epsilon$ \\
\hline $12,13,14,38$ & -0.18 & $-0.84,0.48$ & 0.83 & -0.30 & $-0.94,0.34$ & 0.74 & 0.59 & $-0.31,1.50$ & 1.81 & & & & 0.21 & -0.01 \\
\hline $16,17,19$ & -0.32 & $-0.95,0.30$ & 0.72 & -0.48 & $-1.12,0.17$ & 0.62 & 0.04 & $-0.79,0.86$ & 1.04 & & & & 0.08 & $-0.1 c$ \\
\hline Variance explaine & , \% & & & & & & & & & & & & & \\
\hline $\begin{array}{l}\text { between } \\
\text { villages }\end{array}$ & & 100 & & & 100 & & & 86 & & & 100 & & & 100 \\
\hline $\begin{array}{l}\text { Reference } \\
\text { value }^{c}\end{array}$ & $3.24 \ln -$ & $\mathrm{g} / \mathrm{m}^{3}$ & & $0.97 \ln$ & $-n g / m^{3}$ & & $5.38 \mathrm{Ir}$ & $-n g / m^{3}$ & & - & & & $3.67 \mathrm{ln}$ & $\mu \mathrm{g} / \mathrm{m}^{\approx}$ \\
\hline
\end{tabular}

Burning smoky coal and having $>50 \%$ of households with chimneys was associated with higher levels of outdoor BaP $(\mathrm{GMR}=2.79, \mathrm{p}<0.05$ for smoky coal compared to smokeless coal; GMR $=1.49, \mathrm{p}<0.05$ for villages having $>50 \%$ of households with chimneys compared to those having $\leq 50 \%$ of households with chimneys) when adjusted for the variables shown in Table 4 . However, using smoky coal was associated with a lower outdoor $\mathrm{SO}_{2}$ detection rate $(\mathrm{OR}=$ $0.43, \mathrm{p}<0.05)$. Outdoor $\mathrm{PM}_{2.5}(\mathrm{GMR}=1.86, \mathrm{p}<0.05), \mathrm{BaP}(\mathrm{GMR}=1.46, \mathrm{p}<0.05)$, and NAP $(\mathrm{GMR}=3.17, \mathrm{p}<0.05)$ concentrations were significantly higher in winter, and $\mathrm{BaP}$ concentrations $(\mathrm{GMR}=1.69, \mathrm{p}<0.05)$ were higher in spring and summer compared to the corresponding pollutant levels in autumn. Outdoor $\mathrm{PM}_{2.5}$ and NAP did not vary significantly by coal deposit, but BaP levels in LS site $(G M R=0.44, p<0.05)$ were significantly lower than at other sites. For coal deposits located in northeast Xuanwei, $\mathrm{NO}_{2}$ levels for the smoky coal deposits (i.e. 1,2,4,7,8 and 9) were significantly higher compared to the smokeless coal deposits (i.e. 20, 27). 
In villages with reference entry levels, the log-transformed values for outdoor $\mathrm{PM}_{2.5}, \mathrm{BaP}, \mathrm{NAP}$, and $\mathrm{NO}_{2}$ were $3.24 \mathrm{ln}-\mu \mathrm{g} / \mathrm{m}^{3}, 0.97 \mathrm{ln}-\mathrm{ng} / \mathrm{m}^{3}, 5.38 \mathrm{In}-\mathrm{ng} / \mathrm{m}^{3}$, and $3.67 \mathrm{ln}-\mu \mathrm{g} / \mathrm{m}^{3}$, respectively.

\section{Discussion}

The Global Burden of Disease project (GBD) for 2010 found that household solid fuel use accounted for $12 \%$ of ambient $\mathrm{PM}_{2.5} \mathrm{globally}$, with the regional concentration of ambient $\mathrm{PM}_{2.5}$ in the southern regions of Asia being the highest [19]. Exposure assessment for the GBD also showed substantial exposures occurring in rural areas [20]. Potential sources of rural ambient air pollution may be from households using solid fuels for cooking and heating, from nearby urban and rural sources, and from secondary pollutants at intercontinental scales [7].

Only a handful of studies have reported ambient concentrations in rural areas, as health-damaging air pollution has been considered a largely urban phenomenon [7]. Our study revealed high levels of outdoor air pollution in a rural area of China with a high incidence of lung cancer. The 24-hour geometric mean outdoor $\mathrm{PM}_{2.5}$ concentrations in villages of the two rural counties, $51.6 \mu \mathrm{g} / \mathrm{m}^{3}$ in Xuanwei and $40.2 \mu \mathrm{g} / \mathrm{m}^{3}$ in Fuyuan, are almost two-fold that of the outdoor $\mathrm{PM}_{2.5}$ guideline value set by the World Health Organization $\left(25 \mu \mathrm{g} / \mathrm{m}^{3}\right)$ [21]. Further, measured $\mathrm{PM}_{2.5}$ concentrations were similar to the populationweighted average exposure to $\mathrm{PM}_{2.5}\left(52 \mu \mathrm{g} / \mathrm{m}^{3}\right)$ in China [22], higher than those in rural areas in Hong Kong $\left(24.9-30.0 \mu \mathrm{g} / \mathrm{m}^{3}\right)$ [23], and comparable to levels at suburban sites reported in an earlier study in Guangdong, Wuhan, Lanzhou and Chongqing, China (GM: 39-94 $\left.\mu \mathrm{g} / \mathrm{m}^{3}\right)$ [24].

The geometric means of outdoor BaP were 10.5 and $8.9 \mathrm{ng} / \mathrm{m}^{3}$ in Xuanwei and Fuyuan, respectively, which were up to 105 times as high as the background levels in rural areas of the United States reported by the Agency for Toxic Substances and Disease Registry [25]. Both outdoor BaP and NAP in this rural area of China were much higher than the levels found in the rural Cantabria region in Spain $\left(0.15 \mathrm{ng} / \mathrm{m}^{3}\right.$ for BaP and $\left.<0.01 \mathrm{ng} / \mathrm{m}^{3} \mathrm{for} N A P\right)$ [26]. In Xuanwei and Fuyuan, the combined outdoor BaP and NAP levels were five-fold and two-fold higher than rural air levels in central Taiwan, respectively (1.5 $\mathrm{ng} / \mathrm{m}^{3}$ for BaP and $223 \mathrm{ng} / \mathrm{m}^{3}$ for NAP) [27]. Outdoor NAP levels in our data were even higher than the highest NAP exposure category among occupationally exposed U.S. Air Force personnel [28]. Average BaP levels exceeded the 24-hour criterion of the Chinese national standard $\left(2.5 \mathrm{ng} / \mathrm{m}^{3}\right) \mathrm{by} \mathrm{a}$ factor of two [29].

Varying from 85.1-118.5 across all coal deposits, the arithmetic mean outdoor $\mathrm{NO}_{2}$ concentrations in our study area were $\sim 98 \mu \mathrm{g} / \mathrm{m}^{3}$, two to ten times as high as those found in a rural area in India $\left(4.7-9.6 \mu \mathrm{g} / \mathrm{m}^{3}\right)[30]$ and an industrial city in Turkey $\left(14.0-57.5 \mu \mathrm{g} / \mathrm{m}^{3}\right)[31]$.

Outdoor $\mathrm{SO}_{2}$ detectable concentrations in our study were negligible compared with the levels measured in a rural area in India $\left(2.5-5.2 \mu \mathrm{g} / \mathrm{m}^{3}\right)[30]$ and an industrial city in Turkey $\left(5.9-41.2 \mu \mathrm{g} / \mathrm{m}^{3}\right)[30,31]$. This is consistent with the finding that the rural residents used low sulfur coals in this study area [32]. However, using smoky coal was associated with a significantly lower outdoor $\mathrm{SO}_{2}$ detection rate than using smokeless coal (\%Detect: 21.6 vs $50 \%$ ), which is also consistent with both the observations of indoor $\mathrm{SO}_{2}$ [13] and in a coal composition analysis [32].

In South Asia, regional concentrations of ambient $\mathrm{PM}_{2.5}$ derived from household cooking with solid fuels in 2010 was $8.6 \mu \mathrm{g} / \mathrm{m}^{3}$, which contributed $12 \%$ and $26 \%$ to ambient $\mathrm{PM}_{2.5}$ levels globally and in India, respectively [19]. Although our study was not designed to measure emissions at the outlet of household chimneys, we calculated the ratio of outdoor levels over the average indoor concentrations measured in each village visited in Xuanwei and Fuyuan. The outdoor/indoor (O/I) ratios were 10\% - 30\% for $\mathrm{PM}_{2.5}$ [11], 20\% - 60\% for BaP [12], and 70\% - 80\% for $\mathrm{NO}_{2}$ [13] depending on the various household solid fuels that were used. It is not surprising that $\mathrm{NO}_{2}$ presents a higher $\mathrm{O} / \mathrm{I}$ ratio due to the higher penetration rates of gaseous pollutants. The higher $\mathrm{O} / \mathrm{I}$ ratio for $\mathrm{BaP}$ compared to $\mathrm{PM}_{2.5}$ may imply other outdoor BaP sources, such as from emissions from other households in the village. Taken together, these results suggest that indoor air pollution due to coal combustion in households is a significant source of outdoor air pollution in rural villages.

Ventilated stove and fuel use in rural settings may have different effects on indoor, outdoor air pollution and personal exposures. A previous study of Xuanwei smoky coal use assessed the long-term health benefits of converting from unvented stoves to either stoves with chimneys or portable stoves (which were intended to be lit outdoors before being carried inside for use), and observed reduced indoor air exposures and lung cancer risks [17, 18]. This study is the first to evaluate outdoor air pollution in this rural area that has a high incidence of lung cancer. Installing chimneys to simply discharge pollutants from inside homes to the outdoors may increase outdoor concentrations and as a result not sufficiently reduce the overall exposure to carcinogens; therefore, removal of the pollution source by moving populations up the "energy ladder" towards the use of cleaner fuels (e.g. biogas and electricity) should be strived for.

Meteorological factors may affect the spreading of primary pollutants and the formation of secondary pollutants in rural villages [33]. A study conducted in an urban area of Hong Kong found that temperature, humidity, and solar irradiation played a vital role in the variation of the $0 / I$ ratio, which increased with upward changes of these weather parameters [34]. However, in the current study, seasonal category was found to more accurately predicate the outdoor exposure than meteorological factors.

This study showed that outdoor air pollution in a rural region of China with a high incidence of lung cancer was associated with coal type and the proportion of ventilated stoves in a village. These findings suggest that the further reduction of adverse health effects in rural villages from the indoor burning of coal, will most likely require the use of stoves that reduce environmental exhaust, and ultimately the replacement of coal with cleaner fuel types.

\section{Declarations}

Ethical approval and consent to participant: The study protocol was approved by the institutional review boards of the National Cancer Institute and China National Environmental Monitoring Center. All participants provided written informed consent prior to participating in the study. 
Consent for publication: The content of this publication does not necessarily reflect the views or policies of the Department of Health and Human Services, nor does the mentioning of trade names, commercial products, or organizations imply endorsement by the U.S. Government.

Availability of supporting data: The data supporting the results of this article are included within the article.

Competing interests: The authors declare that they have no conflict of interest.

Funding: This project was supported by the National Institutes of Health Intramural Research Program.

Authors' contributions: QL, RV, NR and FW conceived of and designed the study. BB, WH, JL, JX, JH, LZ, GW, YH, KY and YC participated in data collection. WH and GD conducted the analyses and were primarily responsible for drafting the paper. All authors reviewed and approved the manuscript.

Acknowledgements: The authors would like to acknowledge Jackie King from BioReliance, and Peter Hui and Nathan Appel from Information Management Systems, Inc. for their support.

\section{Authors' information:}

\section{Affiliations}

Occupational \& Environmental Epidemiology Branch, Division of Cancer Epidemiology \& Genetics, National Cancer Institute, National Institutes of Health, Rockville, MD, USA

Wei Hu, Jason Y.Y. Wong, Nathaniel Rothman, Rena R. Jones, Bryan Bassig \& Qing Lan

Institute for Risk Assessment Sciences, Division of Environmental Epidemiology, Utrecht University, Utrecht, The Netherlands

George Downward, Lutzen Portengen \& Roel Vermeulen

Mel and Enid Zuckerman College of Public Health, University of Arizona, Tucson, AZ, USA

Boris Reiss

Qujing Center for Disease Control and Prevention, Qujing, Yunnan, China

Jihua Li \& Jun He

Department of Cardiothoracic Surgery, The Third Affiliated Hospital of Kunming Medical University (Yunnan Cancer Hospital, Yunnan Cancer Center), Kunming, China

Yunchao Huang, Kaiyun Yang \& Ying Chen

School of Public Health, Li Ka Shing Faculty of Medicine, The University of Hong Kong, Hong Kong, Special Administrative Region of China

Jun Xu

Saw Swee Hock School of Public Health, National University of Singapore, Singapore, Singapore

Wei Jie Seow

Department of Epidemiology and Population Health, Albert Einstein College of Medicine, Bronx, NY, USA

H. Dean Hosgood

China National Environmental Monitoring Center, Beijing, China

Linlin Zhang, Guoping Wu \& Fusheng Wei

Corresponding author.

Correspondence to: Wei Hu: wei.hu@nih.gov

\section{References}

1. 7 million premature deaths annually linked to air pollution [http://www.who.int/mediacentre/news/releases/2014/air-pollution/en/]

2. World Health Organization: Ambient air pollution: a global assessment of exposure and burden of disease. Geneva, Switzerland: WHO Document Production Services; 2016.

3. Cohen AJ, Brauer M, Burnett R, Anderson HR, Frostad J, Estep K, Balakrishnan K, Brunekreef B, Dandona L, Dandona R et al: Estimates and 25-year trends of the global burden of disease attributable to ambient air pollution: an analysis of data from the Global Burden of Diseases Study 2015. Lancet 2017, 389(10082):1907-1918. 
4. Loomis D, Grosse Y, Lauby-Secretan B, El Ghissassi F, Bouvard V, Benbrahim-Tallaa L, Guha N, Baan R, Mattock H, Straif K et al: The carcinogenicity of outdoor air pollution. Lancet Oncol 2013, 14(13):1262-1263.

5. Loomis D, Huang W, Chen G: The Intemational Agency for Research on Cancer (IARC) evaluation of the carcinogenicity of outdoor air pollution: focus on China. Chin J Cancer 2014, 33(4):189-196.

6. International Agency for Research on Cancer: Outdoor air pollution/ IARC monographs on the evaluation of carcinogenic risks to humans, vol. 109. Lyon, France: World Health Organization; 2016.

7. Smith KR: Rural Air Pollution: A Major But Often Ignored Development Concern. In: Testimony at the Commission on Sustainable Development Session on Integrated Approaches to Addressing Air Pollution. New York: United Nations; 2006.

8. Zhang JJ, Smith KR: Household air pollution from coal and biomass fuels in China: measurements, health impacts, and interventions. Environ Health Perspect 2007, 115(6):848-855.

9. Mumford JL, He XZ, Chapman RS, Cao SR, Harris DB, Li XM, Xian YL, Jiang WZ, Xu CW, Chuang JC et al: Lung cancer and indoor air pollution in Xuan Wei, China. Science 1987, 235(4785):217-220

10. Barone-Adesi F, Chapman RS, Silverman DT, He X, Hu W, Vermeulen R, Ning B, Fraumeni JF, Jr., Rothman N, Lan Q: Risk of lung cancer associated with domestic use of coal in Xuanwei, China: retrospective cohort study. BMJ 2012, 345:e5414.

11. Hu W, Downward GS, Reiss B, Xu J, Bassig BA, Hosgood HD, 3rd, Zhang L, Seow WJ, Wu G, Chapman RS et al: Personal and indoor PM2.5 exposure from buming solid fuels in vented and unvented stoves in a rural region of China with a high incidence of lung cancer. Environ Sci Technol 2014, 48(15):84568464 .

12. Downward GS, Hu W, Rothman N, Reiss B, Wu GP, Wei FS, Chapman RS, Portengen L, Qing L, Vermeulen R: Polycyclic Aromatic Hydrocarbon Exposure in Household Air Pollution from Solid Fuel Combustion among the Female Population of Xuanwei and Fuyuan Counties, China. Environmental Science \& Technology 2014, 48(24):14632-14641.

13. Seow WJ, Downward GS, Wei H, Rothman N, Reiss B, Xu J, Bassig BA, Li J, He J, Hosgood HD et al: Indoor concentrations of nitrogen dioxide and sulfur dioxide from burning solid fuels for cooking and heating in Yunnan Province, China. Indoor Air 2016, 26(5):776-783.

14. Downward GS, Hu W, Rothman N, Reiss B, Wu G, Wei F, Xu J, Seow WJ, Brunekreef B, Chapman RS et al: Outdoor, indoor, and personal black carbon exposure from cookstoves burning solid fuels. Indoor Air 2016, 26(5):784-795.

15. Lan Q, He X, Shen M, Tian L, Liu LZ, Lai H, Chen W, Berndt SI, Hosgood HD, Lee KM et al: Variation in lung cancer risk by smoky coal subtype in Xuanwei, China. Int J Cancer 2008, 123(9):2164-2169.

16. Wong JYY, Downward GS, Hu W, Portengen L, Seow WJ, Silverman DT, Bassig BA, Zhang J, Xu J, Ji BT et al: Lung cancer risk by geologic coal deposits: A case-control study of female never-smokers from Xuanwei and Fuyuan, China. Int J Cancer 2019, 144(12):2918-2927.

17. Lan Q, Chapman RS, Schreinemachers DM, Tian L, He X: Household stove improvement and risk of lung cancer in Xuanwei, China. J Nat/ Cancer Inst 2002, 94(11):826-835.

18. Hosgood HD, Chapman R, Shen M, Blair A, Chen E, Zheng T, Lee KM, He X, Lan Q: Portable stove use is associated with lower lung cancer mortality risk in lifetime smoky coal users. British Journal of Cancer 2008, 99(11):1934-1939.

19. Chafe ZA, Brauer M, Klimont Z, Van Dingenen R, Mehta S, Rao S, Riahi K, Dentener F, Smith KR: Household cooking with solid fuels contributes to ambient PM2.5 air pollution and the burden of disease. Environ Health Perspect 2014, 122(12):1314-1320.

20. Brauer M, Amann M, Burnett RT, Cohen A, Dentener F, Ezzati M, Henderson SB, Krzyzanowski M, Martin RV, Van Dingenen R et al: Exposure assessment for estimation of the global burden of disease attributable to outdoor air pollution. Environ Sci Technol 2012, 46(2):652-660.

21. Ambient (outdoor) air quality and health [http://www.who.int/mediacentre/factsheets/fs313/en/]

22. Rohde RA, Muller RA: Air Pollution in China: Mapping of Concentrations and Sources. PLoS One 2015, 10(8):e0135749.

23. Cao JJ, Lee SC, Chow JC, Cheng Y, Ho KF, Fung K, Liu SX, Watson JG: Indoor/outdoor relationships for PM2.5 and associated carbonaceous pollutants at residential homes in Hong Kong - case study. Indoor Air 2005, 15(3):197-204.

24. Wei F, Teng E, Wu G, Hu W, Wilson WE, Chapman RS, Pau JC, Zhang J: Ambient concentrations and elemental compositions of PM10 and PM2.5 in four Chinese cities. Environmental Science \& Technology 1999, 33(23):4188-4193.

25. ATSDR (Agency for Toxic Substances and Disease Registry): Toxicological profile for polycyclic aromatic hydrocarbons. Atlanta: ATSDR; 1995.

26. Arruti A, Fernandez-Olmo I, Irabien A: Evaluation of the urban/rural particle-bound PAH and PCB levels in the northern Spain (Cantabria region). Environ Monit Assess 2012, 184(11):6513-6526.

27. Fang GC, Chang KF, Lu C, Bai H: Estimation of PAHs dry deposition and BaP toxic equivalency factors (TEFs) study at Urban, Industry Park and rural sampling sites in central Taiwan, Taichung. Chemosphere 2004, 55(6):787-796.

28. Egeghy PP, Hauf-Cabalo L, Gibson R, Rappaport SM: Benzene and naphthalene in air and breath as indicators of exposure to jet fuel. Occupational and Environmental Medicine 2003, 60(12):969-976

29. Ambient air quality standards (GB 3095-2012) [http://kjs.mep.gov.cn/hjbhbz/bzwb/dqhjbh/dqhjzlbz/201203/W020120410330232398521.pdf]

30. Gupta A, Kumar R, Kumari KM, Srivastava SS: Measurement of NO2, HNO3, NH3 and SO2 and related particulate matter at a rural site in Rampur, India. Atmospheric Environment 2003, 37(34):4837-4846.

31. Bozkurt Z, Dogan G, Arslanbas D, Pekey B, Pekey H, Dumanoglu Y, Bayram A, Tuncel G: Determination of the personal, indoor and outdoor exposure levels of inorganic gaseous pollutants in different microenvironments in an industrial city. Environ Monit Assess 2015, 187(9):590. 
32. Downward GS, Hu W, Large D, Veld H, Xu J, Reiss B, Wu G, Wei F, Chapman RS, Rothman N et al: Heterogeneity in coal composition and implications for lung cancer risk in Xuanwei and Fuyuan counties, China. Environ Int 2014, 68:94-104.

33. Kamens RM, Guo Z, Fulcher JN, Bell DA: The influence of humidity, sunlight, and temperature on the daytime decay of polyaromatic hydrocarbons on atmospheric soot particles. Environ Sci Technol 1988, 22(1):103-108.

34. Chan AT: Indoor-outdoor relationships of particulate matter and nitrogen oxides under different outdoor meteorological conditions. Atmospheric Environment 2002, 36(9):1543-1551.

\section{Figures}

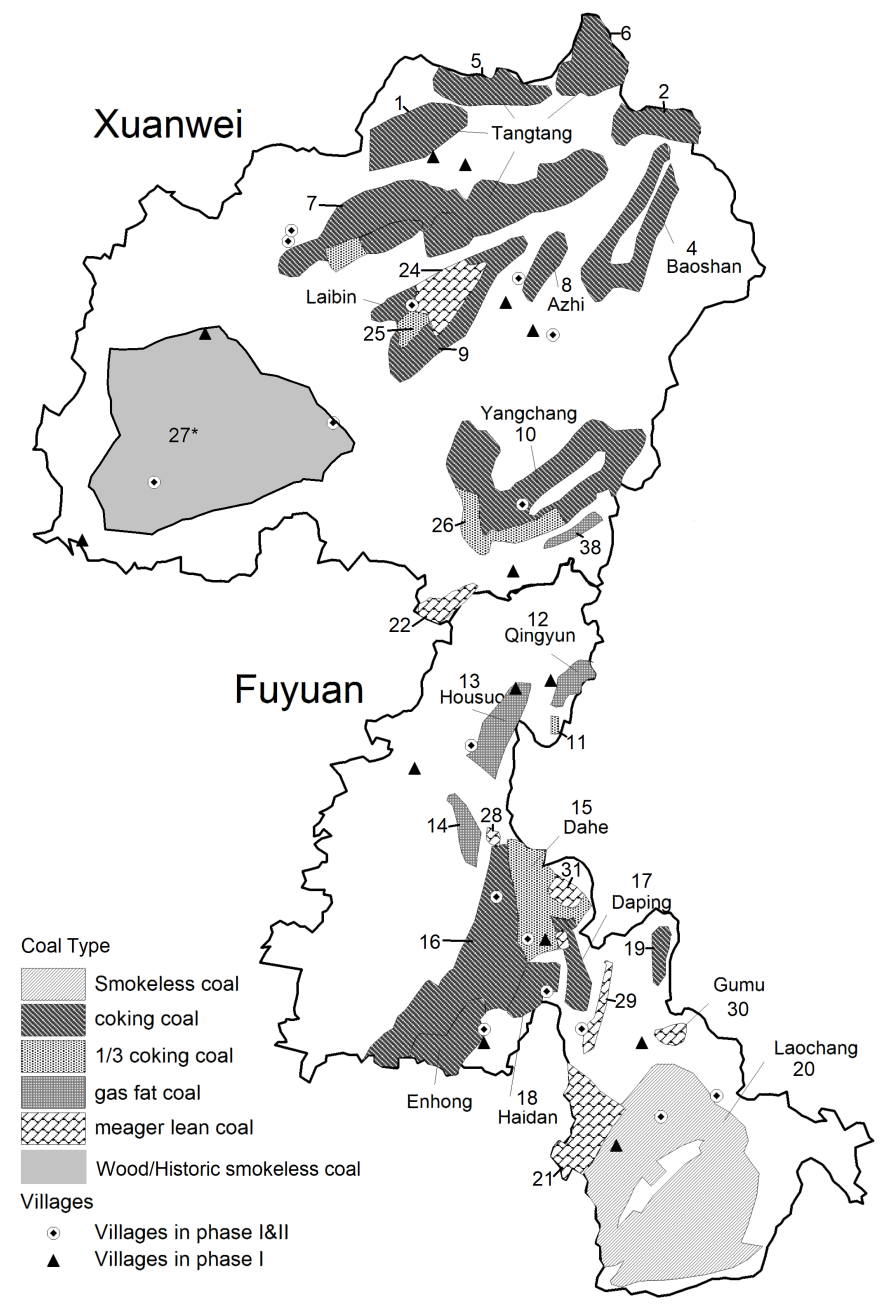

Figure 1

Map of geological coal deposits and study villages in Xuanwei and Fuyuan counties. Classification of coal regions based on the State Standard of China Coal Classification (GB5751-86); 1/3 coking, coking, gas fat, and meager lean coals are subtypes of smoky coal. *Historic smokeless coal deposit. Note: The designations employed and the presentation of the material on this map do not imply the expression of any opinion whatsoever on the part of Research Square concerning the legal status of any country, territory, city or area or of its authorities, or concerning the delimitation of its frontiers or boundaries. This map has been provided by the authors. 